\title{
THE GREAT OBSESSION: AN ORIENTAL RIDDLE
}

\author{
LIEUTENANT-COLONEL D. M. ROBERTS, M.D., F.R.C.P.E., R.A.M.C.
}

The man

Those of us in the Corps who have served in Hong Kong will know of the reputation of Sir Robert Ho. Sir Robert's life (he was born in 1860 and died in 1954) spanned a century of remarkable change in the Far East. The fulcrum of all activity throughout this era was the British Crown Colony of Hong Kong and few would deny that Sir Robert was the Colony's pre-eminent citizen. Knighted by two successive British Sovereigns, he was a leading figure of his time, one of a small group of Eurasians who were looked up to by both the Oriental and the Occidental Communities, representing the trust and interdependence between the two cultures which has been the life-source of Hong Kong since its very beginning.

He was a leading figure in the board rooms of most of the great Far East trading Hongs and in the judiciary and legislature of the Colony, and his reputation was truly international, rubbing shoulders as he did with Kings, Princes, Prime Ministers and Ambassadors.

Throughout the ninety-four years of his life he suffered from a frail constitution and general ill-health. At times it seemed he had a diarrhoeal wasting disease (he never weighed much more than eight stones) and his family consider that the fact that he survived all his contemporaries was due only to his will and to his meticulous, even obsessional, attention to the details of his health and diet.

The obsessional element in his nature is evidenced by his personal diaries, seven volumes of which have recently come into my possession from his grandson, $\mathrm{Mr}$. Eric Hotung. In these diaries he records, day by day, the details of his business appointments, social engagements and-most elaborately-his health and bodily functions.

\section{The language}

The diaries are almost entirely in handwritten Chinese but with a sprinkling of entries in English. I felt that, if only I could surmount the imposing language barrier, it might be possible to uncover a fascinating medical story or even, perhaps, to make a retrospective diagnosis on the evidence revealed. The reality fell a long way short of this, but the entries did reveal some intriguing facets of the personality and personal habits of an eminent man.

I approached Mr. Thorington of the Liguistic Services Department of the Ministry of Defence and I am greatly indebted to him for his help in unravelling the contents of these volumes, I hesitate to use the simple term "translation" because this is inadequate to describe the combination of detective work, intuition and intelligent deduotion that go into a translation from the Cantonese. It is, shall I say, as much an art as a science, and quite an eye-opener to an uninitiate such as me. 
For example, 'hand-written' in terms of Chinese script could refer to characters written in more or less the full form (which would be legible by anyone with an ability to read Chinese) or to oharacters written in cursive script (very difficult for someone not conversant with the style) or even to characters written in "grass-script" which is a more or less personalised shorthand and might well be totally illegible to anyone except the writer. These are not, however, distinct categories: the one form merges into the other and a diarist would probably vary his writing style according to demands of secrecy or even according to mood. Further, the calligraphy itself is crucial. Sir Robert appears to have used a variety of writing instruments, mostly fountain pens and, given that Chinese script is a form of writing in which subtleties of style are of the essence, the difficulties to which this gives rise are obvious. A further problem is to do with names. Names of foods, drugs, patent medicines, herbal medicines and the like are extremely difficult to translate (think, for example of the difficulty a Chinese would have in trying to translate 'Phensic', 'Weetabix' or 'Welsh Rarebit'!) Names of family members, I am told, are no easier. Chinese has an extensive and (to a Westerner) extremely complicated series of expressions denoting family relationships. For example, there is a compound which means, specifically, 'elder male first cousin of a different surname'! This system is intermingled with numbers to indicate order of birth, favourite names, nicknames and so on. Now, I hope, you will understand how indebted I am to Mr. Thorington!

\section{The diaries}

The seven volumes of Sir Robert's diaries represent the years 1941, 42, 48, 49, 52 , 54 and 1956 and the general nature of them changes very little over this 15-year period. This is not surprising for a writer who was, after all, 80 years old in 1941 and, one may imagine, already set in his ways.

A typical daily entry (one is shown in Figure 4) is concerned with the meticulous, but totally unembroidered enumeration of the days events. They record diet, medication, personal activities and bodly functions and business or recreational appointments. I was disappointed to see that, although the facts were recorded, the writer's reaction to those facts was never revealed. His state of mind or mood are not touched upon; what transpires between himself and the people he meets remains unknown; when he receives a visit from the doctor, even the doctor's opinion remains a secret. It is difficult to avoid the feeling that the writer was, in these later years, an obsessively meticulous valetudinarian whose preoccupation with his own regimen precluded any interest in or enjoyment of external matters.

Or could it be, I wonder, that these are "public diaries" and that the more sensitive aspects of Sir Robert's life were consigned to other more private volumes? It would be quite in keeping with common procedures for a prominent citizen of Hong Kong to maintain a separate repository of arcane confessions; but this is speculation.

The diary for 1941 is the only volume written in the old Chinese style-from back to front, with the characters running down each page and from right to left. 


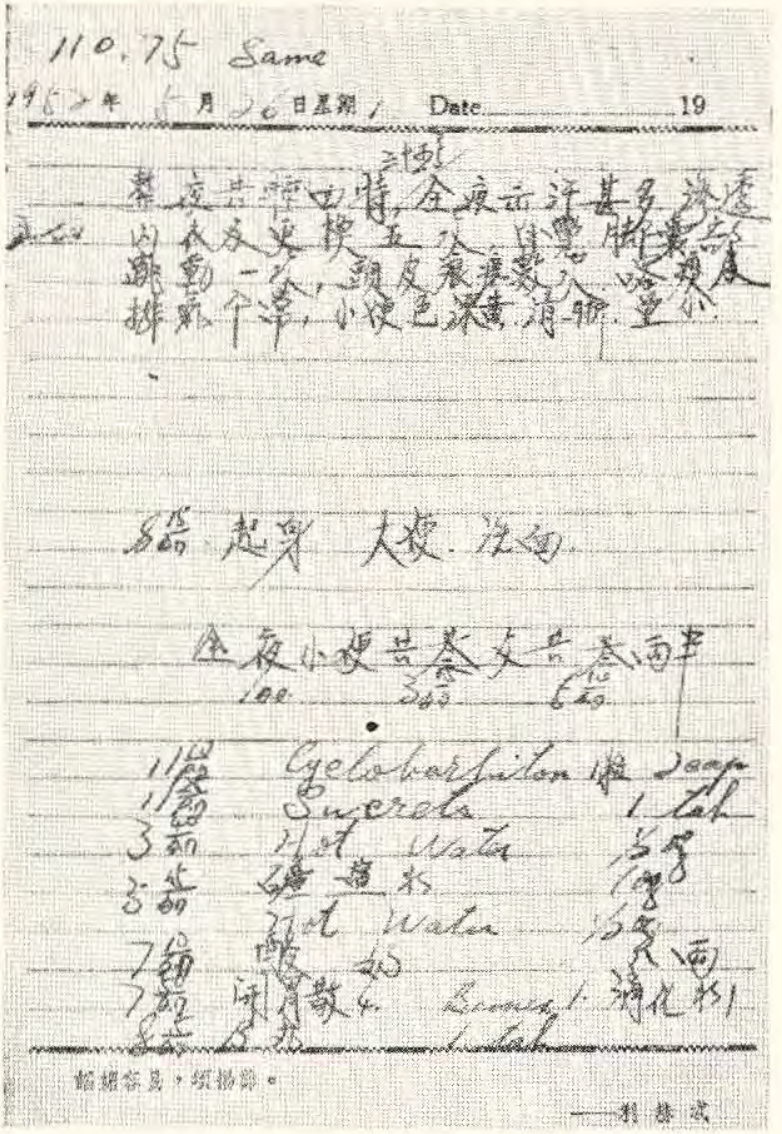

Fig. 1, Diaries of Sir Rohert Ho, the entry for 26th May, 1952. It reads:" Weight $110^{\frac{3}{4}}$ -same. Slept 4 hours the whole night. Sweated a great deal all night and changed sleeping attire 5 times. Felt tremors in the legs and pains in the head several times... colour of urine deep yellow, quantities small. 8.15 a.m. got up. Bowel movement. Washed face. During the entire night urinated 3 times-1.00, 3.15 and $5.10-$ altogether $3 \frac{1}{2}$ ounces: 11.10 p.m. Cyclobarbiton 1 grain2 cap: 11.25 p.m. Sucrets 1 tab: 3.40 a.m. Hot wator $\frac{1}{2}$ oz: 5.15 a.m. Mineral salts liquid $1 \mathrm{oz}$. Hot water 1 oz: 7.10 a.m. Sour milk 8 oz: 7.50 a.m. 4 "K'aiwei-san", 1 Bemax, 1 Digestion tablet: 8.15 a.m. 1 (vitamin?) B tablet.

Presumably because of this there is a minimum of entries in English, since the book has to be turned sideways to accommodate these in the text. At the end of the volume there appear some accounts of expenditure on patent medicines and special foods, including the intriguing item of 25 Hong Kong dollars for one box of "Dutch Milk".

The writer's weight is recorded every day, and it is notable that his weight fell steadily throughout the year from $132 \mathrm{lb}$. to $114 \mathrm{lb}$.

Throughout 1942 the diary is at its least legible. It is not until December that the entries suddenly become relatively easy to decipher and this improvement in clarity, precisely and intriguingly, marks the alteration of the early morning medication from some sort of mineral drink to a mineral-salt biscuit (a charcoal biscuit, I wonder?). Of course, the reason for an improvement in clarity could equally be the acquisition of a new pen or a resolution for calligraphic reform. By now Sir Robert's body weight was down to $85 \mathrm{lb}$.- -an alarming loss over two years, by any standards.

Six years later, in 1948, no doubt reflecting the extension of social and business life after the end of the war, many European names begin to appear in the diary, 
and from now onwards we see names like Jack Braga, Horace Kadoorie, Tony Keswick and several of the Marden family, all names familiar to anyone who knows Hong Kong.

During 1949 Sir Robert spent several months in Europe. In England we read of visits to Regent's Park Zoo (where his preoccupation with diet extends even to the animals; he makes notes of what some of them were eating!), and to Henley Regatta, interspersed with meetings with many notables. He was presented to their Majesties the King and Queen on the 7th July. He met Mr. and Mrs. Churchill, the Sultan of Johore, the Lord Chancellor, The Lord Chief Justice, and even, on 4th July, Bernard Shaw, then in his 93rd year. Before returning to Hong Kong he toured some of the Capitals of Europe and had meetings with the King and Queen and Prince Axel of Denmark, King Haakon of Norway, the Crown Prince of Sweden, and the President of the French Republic.

His health was never far from his mind and whilst in London he was seen twice by Dr. Daniel Davies (a Royal Physician and old chief of mine when I was a student at Gray's Inn Road), by Dr. Thomas, a skin specialist, and by a Professor Gerard who appears to have been a physician of international repute who probably visited London for the express purpose.

Even in Europe Sir Robert remained captive to his obsessional nature. The poor man meticulously records, for example, the ambient temperature in each of the hotel rooms in which he stayed.

From 1952 onwards the medical records become increasingly more detailed. For long periods we see that he took and recorded his pulse and respiration rates from ten to twenty times a day, and his temperature some five to ten times. The entry for May 26th 1952, in Figure 1, is typical, and shows his complete fixation on his bodily functions.

The last recorded entry is for April 25th 1956, when Sir Robert was 94 years old. His state of health was obviously parlous, although his hand-writing, albeit shaky, remained neat and reasonably legible to the end. He records that, in the morning, he was able to recognise visitors, but felt worse in the afternoon, when he could not recognise people. In the morning a female relative came and gave him an injection of some substance the nature of which is unclear, only the character for 'sugar' being recognisable- "but it was very difficult to perform the injection. The doctor came in the morning, but did not given me any injections." With this sentence the diary ends.

\section{The diagnosis}

Is it possible to make a retrospective diagnosis from the evidence of these diaries? Clearly it is not, apart from the obvious one of "obsessional personality." One may speculate about such conditions as tropical sprue and irritable bowel syndrome, but there is no hard evidence here. He takes a very sparse diet which is mainly liquid-numerous bowls of sour milk, and various broths and mineral preparations are prominent, but an ordinary solid meal is a rare enough event to 
warrant special comment: on 23rd April 1948, "Took solid dinner" is recorded prominently at the head of the page. There was certainly an intense pre-occupation with bowels: each and every motion was recorded, its consistency, and usually its volume. Colonic irrigation and enemas figure frequently as an integral part of the daily routine. He dwells closely on his body weight, too, and records it daily. Sometimes he deducts the weight of the motions from his body weight. A three-day sequence in 1948 caught my eye: 4th April: "Weight 89.75 same", 5th April: Weight, 89.25. Minus .50 loss due to exertion in entertainment". 6th April "Weight 88.50 Minus .75. Loss due to exertion in fixing my hearing aid." Other entries during the same period leave one with a sense of sadness. 29th June: "Hurt by shoe horn 3 times." 12th July: "a very bad night due to gas and 2 motions during bath. Got to sleep at 4 a.m." 20th January: "Came home very tired. Pulse up to 72 for a long time." And so it continues, a catalogue of washing ('self', 'feet', 'hair') pill-taking (sedatives, vitamins, minerals, and several with intriguing names such as "Li-tu-pu-t'ien" tablets and "assist leg-strength" pills) and persistent insomnia.

Sir Robert Ho was a great man: he also had a great obsession. Did his obsession result in his alimentary and bowel problems or did the intestinal malady cause the obsession?

Was he, indeed, always so afflicted, or did these burdens descend upon him only. in his later years? These diaries do not reveal the answers: but in their failure they never cease to fascinate.

\section{Acknowledgements}

I am grateful to my friend, Mr. Eric Hotung, for giving me some of his grandfather's diaries, and to Mr. J. Thorington of MSL/LS for their translation.

\section{SENIOR APPOINTMENTS}

Brigadier T. S. Hart, M.B., B.S., M.R.C.S., L.R.C.P., M.F.C.M., D.P.H. D.T.M.\&H., p.s.c., was appointed Director of Medical Services, United Kingdom Land Forces, with effect from 1 January, 1978, in the rank of Major-General, in succession to Major-General S. E. Large, M.B.E., Q.H.P., M.D., F.R.C.P. (Ed.), F.R.C.P.(Lon.) who has retired.

Brigadier D. W. Bray, M.B., B.S., M.F.C.M., D.T.M.\&H., p.s.c., is to be appointed Deputy Director-General of Army Medical Services, with effect from 3 March 1978, in succession to Major-General D. G. Milne, Q.H.S., M.B., Ch.B., F.F.C.M., D.P.H., who is retiring.

Brigadier N. G. Kirby, O.B.E., M.B., Ch.B., F.R.C.S., is to be appointed Director of Army Surgery, with effect from 12 March, 1978, in succession to Major-General A. P. Dignan, M.B.E., Q.H.S., M.B., F.R.C.S.(I), who is retiring.

Colonel A. R. Worthington, M.B., Ch.B., M.F.C.M., D.T.M.\&H., is to be appointed Commandant R.A.M.C. Training Centre, in the Local Rank of Brigadier, with effect from 20 March 1978, in succession to Brigadier D. W. Bray, M.B., B.S., M.F.C.M., D.T.M.\&H., p.s.c. 